\title{
Apresentação
}

\section{Instituições escolares: discursos e experiências de inovação pedagógica na escolarização primária}

O dossiê ora apresentado contém 10 artigos que têm como temática central instituições escolares, discursos e experiências de inovação pedagógica para e na escolarização primária no século XX. Essa escola desempenhou papel significativo durante quase todo o século XX como lugar de aprendizagem de saberes necessários à modernização social. Esteve, sobretudo, vinculada à função civilizadora imprescindível para levar a cabo um projeto de nação que muitos governantes, lideranças políticas e educadores pretenderam e buscaram consolidar no Brasil e na Europa. Por isso, experiências inovadoras foram levadas a cabo com tal finalidade. Abordá-las da perspectiva da inovação, entendida como numa ampla acepção que aponta, portanto, para diferentes compreensões, se entende ser necessário nessa proposta de dossiê.

Assim, visando corresponder a esse escopo, os artigos trazem distintas temáticas que, de diferentes modos, incorporam aquele tipo de escola à formação de professores, ou mesmo aos dispositivos pedagógicos e/ou materiais pedagógicos que serviram e testemunham o trabalho do docente no ensino primário.

Desse modo, as pesquisadoras Thais Bento Faria e Analete Regina Schelbauer abordam, no artigo intitulado Modernização do "sertão" paranaense: atuação de Erasmo Pilotto e Diva Vidal na inovação de práticas pedagógicas (1940-1960), a atuação destes educadores, enquanto sujeitos históricos, e as estratégias delineadas para “modernizar" a prática pedagógica das escolas primárias rurais, por meio das Escolas 
Normais, da imprensa pedagógica e de documentos normatizadores e orientadores, analisados em diálogo com a historiografia da educação paranaense.

Argentina Pereira Gomes: disseminação de "inovações" didáticas na educação primária na década de 1930, de autoria de Márcia Cristiane Ferreira Mendes, Lia Machado Fiuza Fialho e Charliton José dos Santos Machado, apresenta estudo biográfico sobre Argentina Pereira Gomes (1916 a 1962), normalista e professora em João Pessoa na Paraíba. Situa a sua formação e inserção no magistério, procurando responder sobre o ideário pedagógico levado a cabo em seu processo formador na escola primária onde atuou, chamando atenção para a atuação inovadora da educadora por meio de sua ampla inserção social.

Em Historia y (des)memorias del icónico libro ¿Maestro pueblo o maestro gendarme? de María Teresa Nidelcoff, a autora Natalia Carolina García toma como base o livro de Nidelcoff que circulou na segunda metade do século XX na América Latina e que foi editado no Brasil sob o título Uma escola para o povo. Imbricada a este está uma narrativa que deixa vir à tona o envolvimento e participação de uma mulher atenta, preocupada e engajada com questões sociais mais prementes do seu tempo, representadas pelas desigualdades sociais. O livro foi escrito no sentido de divulgar modos de emancipação de sujeitos em condições sociais desfavorecidas.

Wanessa Gorri de Oliveira e Elaine Rodrigues, no artigo intitulado A instrução pública e a escola primária paranaense nas charges de O Olho da Rua, tomam como fonte e objeto de estudo a revista O Olho da Rua, entre 1907 e 1911, cuja análise foi balizada pela história cultural. As autoras identificam o periódico como "um suporte material e meio de difusão do que era considerado retrógrado na instrução pública e no fazer prático da escola primária no início do século XX no estado do Paraná” e analisam as críticas que esse periódico fez circular, por meio de charges, sobre a instrução pública e os encaminhamentos práticos vigentes nas escolas primárias paranaenses.

As autoras Alessandra Cristina Furtado, Maria do Carmo Brazil e Edvonete Souza de Alencar trazem o Ensino de divisão numa escola rural de Dourados-MS (1989) como tema do artigo que se insere nas abordagens sobre a história das instituições escolares rurais no sul de Mato Grosso (atual Mato Grosso do Sul). No estudo, as autoras analisam o caderno escolar de uma professora de matemática da zona rural 
do interior de Mato Grosso do Sul, a partir da indagação sobre como ocorreu o ensino matemática nessa escola — especificamente, o ensino de divisão.

No texto intitulado Escolas complementares na região fronteiriça do ex-Contestado (1928-1938), Márcia Marlene Stentzler e Liane Maria Bertucci retratam a criação e as transformações das Escolas Complementares de Porto União (SC) e União da Vitória (PR), com destaque para os aspectos da formação de professores, nos municípios investigados, e suas relações com o entorno dessas instituições. Destacam as singularidades destas escolas acerca não somente do atendimento ao alunado, mas também da prevalência de uma sobre a outra e suas influências em cada uma das cidades.

$\mathrm{O}$ artigo de Reginaldo Rodrigues da Costa sobre $O$ Centro de Treinamento de Pessoal do Estado do Paraná e a capacitação e aperfeiçoamento do professor analisa as ações de treinamento, com fins de aperfeiçoamento e capacitação de professores públicos, desenvolvidas pelo governo do Estado do Paraná durante o período de 1961 até 1982, adequadas aos ditames da Lei no $5.692 / 71$.

Robert King Hall e a expansão da escola rural no estado de Sergipe (1947-1951) é o título do artigo escrito por Rony Rei do Nascimento Silva, Ilka Miglio de Mesquita e Vera Maria dos Santos, no qual retratam o processo de expansão da escola primária rural, sem precedentes na história do estado Sergipe, a partir das diretrizes propostas pelo professor Robert King Hall — movimento que abarcou não apenas as iniciativas do governo local, mas que esteve relacionado às políticas nacionais e internacionais para a educação rural.

Rossano Silva, no trabalho intitulado A obra Prática da Escola Serena: autoeducação e formação cultural como princípios educativos, analisa a obra de Erasmo Pilotto e a identifica como uma síntese das ações protagonizadas pelo intelectual nas instituições educacionais em que atuou. Destaca as ações realizadas no campo educativo que propiciaram a integração entre cultura e educação e enfatiza o papel atribuído à cultura e à autoeducação como princípios educativos.

Por fim, o texto de Erenildo João Carlos $O$ enunciado do cinema como inovação pedagógica da prática educativa escolar brasileira retrata o cinema como inovação pedagógica na prática educativa escolar brasileira, um ensaio que contém uma abordagem sobre o cinema como dispositivo pedagógico inovador na prática educativa brasileira, com 
destaque aos contributos contemporâneos do cinema à cultura educativa em sentido amplo.

Além de artigos do dossiê, a Revista Diálogo Educacional contempla a publicação de artigos sobre temas educacionais, que certamente inspirarão a análise e a reflexão de estudantes e pesquisadores.

O primeiro artigo, Práticas docentes mediadoras da aprendizagem: laboratório de informática e dispositivos móveis, é de autoria de Eliana Maria Sacramento Soares, Amanda Souza Santos e Eliana Rela. Nele, são apresentados “os resultados de uma pesquisa que buscou compreender como os professores utilizam o laboratório de informática e os dispositivos móveis na escola", tendo como fundamentação teórica a teoria sociointeracionista de Vygotsky. O corpus constituiu-se "a partir de entrevistas semiestruturadas com professores do Ensino Fundamental, categorizadas segundo a análise textual discursiva". Os resultados mostraram que "os professores estão atuando na busca para inserir os recursos do laboratório e dispositivos móveis em suas práticas", com as possibilidades que conhecem, utilizando-as como incrementadoras, ou ao menos para tornar suas aulas mais atrativas. O estudo trouxe também dados sobre práticas mediadoras "com potencial para desencadear nos alunos processos internos de significação, de maneira que a ação realizada com auxílio desses recursos digitais possa funcionar [...] como ação mediadora da aprendizagem”. Dessa forma, desloca-se o foco da tecnologia em si, no processo de ensino e aprendizagem, para "as relações que podem ser estabelecidas entre ela e as práticas pedagógicas realizadas por seu intermédio”.

Na sequência, Margarita Victoria Rodriguez, André Malina e Caroline Correia Maciel, em texto intitulado Formação inicial de professores: contradições do Programa Institucional de Bolsas de Iniciação à Docência (PIBID), buscam "explicitar contradições presentes nas políticas de formação inicial de professores, especialmente aquelas que se destacam no interior do Programa Institucional de Bolsas de Iniciação à Docência (PIBID)". No artigo, as "relações estabelecidas entre o aluno bolsista e as dinâmicas do programa referem-se ao ponto central de investigação e análise”. Para isso, "o procedimento metodológico adotado foi a análise da legislação que regula o programa e a utilização de entrevistas semiestruturadas". As principais contradições encontradas nos dois eixos de investigação apontam para "a distorção na atuação do pibidiano 
quando realiza sua formação prática na escola pública" e para "a dificuldade em garantir a permanência desses acadêmicos de licenciatura em seus cursos”.

Com o título Significações de Estética: desafios para a educação estética em um curso superior de Design, o artigo de Humberto Costa e Tania Stoltz trata da identificação das significações de Estética “junto a discentes de um curso superior de Design, tendo em vista a Educação Estética". Para tanto, foi realizada uma revisão bibliográfica, seguida de um estudo de caso. Como resultado, três significações foram encontradas: 1) Estética é aparência; 2) Estética como categorias estéticas; 3) Estética como conhecimento sensível.

Os autores Rodrigo Otávio dos Santos, Alvino Moser e Thereza Lima, em Hipertexto como mediador pedagógico, tratam do hipertexto e da sua utilização no processo de aprendizagem. Em pesquisa de cunho bibliográfico, discutem a questão da mediação na aprendizagem e do hipertexto como importante mediador na contemporaneidade. O objetivo do estudo é "trazer algumas reflexões que mereçam ser consideradas e analisadas, para um melhor entendimento do fenômeno da aprendizagem mediada no século XXI”.

Adiante, Rita Vieira Figueiredo, Silvia Roberta da Mota Rocha e Jean Robert Poulin, motivados pela relevância da língua escrita na participação social e na subjetivação, e considerando a dificuldade de sua apropriação por pessoas com deficiência intelectual, elaboraram o estudo Contribuição da inclusão digital na afirmação de sujeitos com deficiência intelectual. Nele, investigam "os efeitos da comunicação digital via Facebook na emergência de estratégias cognitivas e na subjetivação de pessoas com deficiência intelectual em contexto de mediação. Trata-se de uma pesquisa qualitativa com orientação sócio-histórica". O estudo permitiu "concluir que a comunicação digital via Facebook contribuiu para o processo de inclusão digital dos sujeitos, desnaturalizando a ideologia da deficiência/normalidade, importante aspecto fomentador de escolas e sociedades acolhedoras".

Os pesquisadores Gabriel Francisco Cevallos, Verónica Sofia Ficoseco e Edvaldo Souza Couto, em "Enseñar lo que se ignora": una aproximación desde la formación docente y la evaluación de aprendizajes sobre tecnologías digitales en el Ecuador, buscaram contrastar analiticamente as capacidades de estudantes de educação básica e bacharelado e professores em formação, a respeito das tecnologias digitais. Para tanto, 
foram utilizados os "Estándares de evaluación del aprendizaje" do Ministério da Educação do Equador e os perfis de egresso obtidos da oferta educativa universitária equatoriana no campo da educação. Como estratégia metodológica, "foram utilizados elementos de análise de redes e análise de conteúdo" aplicados aos mencionados documentos. Os resultados permitiram inferir uma perspectiva instrumental, tanto na oferta quanto nos padrões de avaliação dos estudantes.

Partindo da premissa de que "a Pedagogia, enquanto campo teórico-prático, produz diversos enunciados para significar as práticas pedagógicas escolares, desde a Modernidade", João Francisco Lopes de Lima apresenta o estudo A morte da Pedagogia? Os fundamentos modernos da educação escolar frente aos desafios da pós-modernidade numa perspectiva histórico-filosófica. Explica que a partir "do anúncio da morte da metafísica e da morte do sujeito, o pós-moderno representaria também a morte da Pedagogia, já que sucumbem as categorias que lhe são estruturantes". O estudo, "de caráter bibliográfico, sistematiza argumentos para caracterizar esse cenário social e cultural e refletir sobre a possibilidade de a Pedagogia enfrentar o relativismo e a falta de expectativas quanto ao futuro", tidos como "típicos desse cenário, diante da necessidade de continuar gerando discursos que possam amparar as práticas pedagógicas escolares".

Segue-se o artigo de Eldon Henrique Mühl e Rosana Cristina Kohls, O sentido de uma vida examinada: a importância da pedagogia socrática na educação contemporânea. Tendo “como referência as reflexões de Martha Nussbaum relativas ao tema do sentido de uma vida examinada na educação contemporânea", "a análise centra-se no seguinte questionamento: qual a importância de uma vida examinada e quais as implicações dessa condição para a formação do sujeito na atual sociedade complexa e plural?” A partir do diagnóstico feito por Nussbaum a respeito da "tendência mundial de se reduzir a educação a um processo de capacitação para o mercado”, o artigo busca “avaliar a importância e as exigências das reflexões da pensadora americana ao propor uma educação na perspectiva socrática, apontando a necessidade da reflexão e o desenvolvimento da capacidade de argumentação como bases da formação pedagógica".

O pesquisador Juarez José Tuchinski dos Anjos apresenta o estudo $A$ documentação da Câmara dos Deputados: fonte para a história da instrução no Império (1826- 
1834), cujo objetivo foi "identificar e apontar as características e possibilidades da documentação existente no Arquivo Histórico da Câmara dos Deputados, em Brasília (DF), com vistas à produção de fontes para o estudo da história da instrução elementar no Brasil Império”. Cronologicamente, trata do período de 1826 a 1834, "fase da centralização do ensino elementar imperial". Suas conclusões "apontam para a hipótese de que da documentação custodiada no Arquivo Histórico da Câmara dos Deputados emerge um duplo testemunho para a pesquisa sobre a história da escolarização no Império”. Assim, “de uma parte, as diferentes atitudes políticas em torno da escola e da escolarização da infância no país”, e, de outra, sentidos e significados sobre a história da educação na fase estudada, ainda pouco observados, "mas que podem vir a ser mais bem evidenciados pelo estudo do tipo de escola e escolarização que ali se vinha produzindo".

Encerrando este número da Diálogo Educacional, Aires Bonifacio Mombassa e Eucidio Pimenta Arruda, em Educação a Distância em Moçambique: perspectivas para a inclusão da população no ensino superior, discutem "as perspectivas de inclusão social, econômica e educacional que a Educação a Distância (EaD) apresenta a Moçambique, na perspectiva de proporcionar, em curto prazo, possibilidade de aumento da idade média de formação da população moçambicana em níveis da educação primária, da educação secundária e do ensino superior”. Esclarecem que a EaD, em Moçambique, apesar de nos últimos anos ter vivido um crescimento significativo, ainda constitui uma modalidade de formação desafiadora, seja na perspectiva da resistência interna a ela, seja na dimensão de se desenvolver um sistema de formação a distância que se configure em um amplo espectro de formação em massa que possa evidenciar um salto qualitativo do país frente aos indicadores internacionais de escolaridade. Como resultado, os autores entendem que, apesar dos baixos números e das dificuldades atuais para oferta da $\mathrm{EaD}$, há um potencial imenso de crescimento da $\mathrm{EaD}$ que, possivelmente, representaria "um grande salto educacional e inclusivo a Moçambique".

Desejamos que a leitura dos artigos que compõem o Dossiê "Instituições Escolares: discursos e experiências de inovação pedagógica na escolarização primária no século XX", cujo objetivo foi reunir trabalhos que abordassem o papel significativo que a escola primária desempenhou como um lugar de aprendizagem de 
saberes necessários à modernização social, por meio de experiências inovadoras, conduza a reflexão dos sentidos atribuídos ao conceito de inovação no âmbito da história da educação brasileira ao longo do século XX e nos possibilite refletir sobre as acepções que a palavra inovação tem ocupado no cenário educacional da atualidade. Com este intuito, esperamos contribuir com o diálogo em torno da formação de professores e de novos pesquisadores no âmbito da história da educação.

Ao coletivo de pesquisadores que contribuíram com suas narrativas, agradecemos. Ao público, fica o nosso convite à leitura!

ROSA LYDIA TEIXEIRA CORRÊA (PUCPR)

AnALETE REgina Schelbauer (UEM) Alboni Marisa Dudeque Pianovski Vieira (PUCPR) 